\title{
INOVASI PENGEMBANGAN METODE PEMBELAJARAN DENGAN MENGGUNAKAN REAL AVATAR-BASED LEARNING DALAM PENDIDIKAN KEPERAWATAN: A BRIDGE CONNECTION THEORY AND PRACTICE DI STIKEP PPNI JAWA BARAT
}

\author{
Heni Purnama', Dhika Dharmansyah², Nyanyu Nina Putri Calisane ${ }^{3}$, Linlin \\ Lindayani ${ }^{4}$ \\ 1,2,3,4 Sekolah Tinggi Ilmu Keperawatan PPNI Jawa Barat, Indonesia \\ email: linlinlindayani@gmail.com
}

\begin{abstract}
Virtual learning is one of the learning methods that are considered effective and efficient in improving skills and soft-skills. The purpose of this study was to identified the effectiveness of the application of learning method using avatar-based learning on self-directed learning (SDL) which was one of the main competencies of nursing education. The research was quasi experiment with one group of intervention. Respondent in this research was nursing student of stratum 1 (S1) of level 4. Instrument Self-Directed Learning Instrument (SDLI) was used to measure SDL. The paired $t$ test was used to evaluate the effectiveness of the avatar-based learning method on SDL. This study was conducted on 40 students. Prior to the intervention, the mean score for the total score was $72.3(S D=8.97)$. Result of paired $t$ test to SDL value before and after applied method real-avatar based-learning show that $p$ value $=0,001$. There is an increase of the average SDL of 4.56. Based on the above, it can be concluded that real avatar based-learning method can improve SDL of nursing students.
\end{abstract}

Keywords: Simulation, real avatar-based learning, self-directed learning, nursing

\begin{abstract}
ABSTRAK
Virtual learning merupakan salah satu metode pembelajaran yang dinilai effektif dan efisien dalam meningkatkan keterampilan dan soft-skill. Tujuan dari penelitian ini adalah untuk mengidentifikasi efektifitas penerapan metode pembelajaran menggunakan avatarbased learning terhadap self-directed learning (SDL) yang merupakan salah satu indikator dari kompetensi utama pendidikan keperawatan yaitu pembelajaran sepanjang hayat. Jenis penelitian yang digunakan adalah kuasi eksperimen dengan satu kelompok intervensi. Responden dalam penelitian ini adalah mahasiswa keperawatan strata 1 (S1) tingkat ke-4. Instrument Self-Directed Learning Instrument (SDLI) digunakan untuk mengukur $S D L$. Uji paired $t$ digunakan untuk mengevaluasi efektifitas metode avatar-based learning terhadap SDL. Penelitian ini dilakukan pada 40 mahasiswa. Sebelum dilakukan intervensi, nilai rata-rata untuk total skor adalah $72.3(S D=8.97)$. Hasil uji paired t test terhadap nilai SDL sebelum dan sesudah diterapkan metode real-avatar based-learning meunjukan bahwa $p$ value $=0,001$. Terdapat peningkatan rerata $S D L$ sebesar 4,56 . Berdasarkan hal tersebut maka dapat disimpulkan bahwa metode real avatar basedlearning dapat meningkatkan SDL mahasiswa keperawatan.
\end{abstract}

Kata kunci: Simulasi, real avatar-based learning, self-directed lerning, keperawatan 


\section{PENDAHULUAN}

Metode student centered learning, dimana salah satu jenisnya adalah Problem-Based Learning (PBL) menjadi salah satu metode pembelajaran yang banyak digunakan di insitusi pendidikan keperawatan. Tujuan pembelajaran agar peserta didik tidak hanya tahu dan mengerti, namun paham dan mampu mengembangkan sendiri ilmu yang mereka peroleh. Dalam metode pembelajaran problem based learning (PBL), mahasiswa diberikan kasus dan dituntut untuk bisa memahami kasus tersebut secara keseluruhan. Mereka juga diharapkan untuk mampu membayangkan jika kondisi dalam kasus tersebut terjadi (Cheng, 2010). Akan tetapi, pada kenyataannya, mahasiswa memiliki pengalaman yang kurang bahkan mungkin tidak ada pengalaman langsung merawat pasien dengan berbagai situasi yang komplek (Choi, 2014). Aahasiswa juga dituntut untuk bisa memenuhi tujuan objektif pembelajaran yang sudah ditentukan, padahal sebenarnya fasilitas dan sarana seperti sumber buku juga tidak tersedia lengkap. Disamping itu, rasio pengajar dan mahasiswa yang tidak berimbang, sehingga ketika mahasiswa mengalami kesulitan dan membutuhkan feedback yang cepat, sering kali pengajar tidak mampu memenuhinya dikarenakan kesibukan yang banyak (Cheng, 2010). Kondisi tersebut membuat mahasiswa berada dalam kondis yang tidak jelas mengenai apa yang harus dilakukan dan apakah yang dilakukannya tersebut tepat atau tidak (Tucker, 2015). Dengan demikian dibutuhkan suatu inovasi metode pembelajaran yang baru untuk meningkatkan kualiatas pendidikan keperawatan di Indonesia.

Virtual learning merupakan salah satu metode pembelajaran yang dinilai effektif dan efisien terutama dalam meningkatkan keterampilan termasuk soft skill (Choi, 2014). Konsep dasar dari metode ini adalah dengan penggunaan teknologi komputer dimana semua elemen termasuk lingkungan, situasi, dan manusia didesain sedemikian rupa seperti kondisi nyata (Wikipedia, 2016). Akan tetapi penggunaan metode virtual dengan memanfaatkan teknologi internet dan komputer membutuhkan biaya yang sangat mahal. Sebagi contoh studi yang dilakukan di Taiwan tahun 2015, untuk dua kasus yang dikembangakan membutuhkan dana melebihi dari satu milyar rupiah. Penggunaan metode virtual dengan web-based itu tidak bisa dimanfaatkan oleh banyak institusi pendidikan terutama dinegara berkembang. Disamping itu, dibutuhkan akses internet yang bagus dan komputer dengan spesifikasi yang bagus diutamakan didukung dengan hardware GEFORCE karena program yang diinstal merupakan salah satu program yang berat. Selain harus memiliki teknologi yang bagus, dibutuhkan juga ahli teknologi infomatika dan desain grafis yang mampu membuat virtual-web based.

Keterbatasan fasilitas dan sumberdaya yang dimiliki insitusi keperawatan, terutama dinegara berkembang, memerlikan ide inovasi dimana konsep virtual learning ini bisa diterapkan tanpa menggunakan webbased. Hal ini membuat proses virtual learning bisa lebih efektif dan tidak membutuhkan biaya yang sangat mahal.

Selain inovasi dalam hal fasilitas, diperlukan juga inovasi pada para tenaga perngajar, sehingga mereka masih bisa bekerja dengan baik meskipun memiliki keterbatasan dalam hal fasilitas pendukung. Tujuan dari penelitian ini adalah untuk mengidentifikasi efektifitas 
metode pembelajaran real avatar-based learning terhadap peningaktan selfdirected learning mahasiswa.

\section{METODE PENELITIAN}

Penelitian menggunakan desain quasi eksperiment dengan rancangan pretest-postest without control group design. Penelitian ini dilakukan pada mahasiswa keperawatan $\mathrm{S} 1$ yang sedang mengikuti pembelajaran dan ujian praktikum mata kuliah KMB III sistem persyarafan.

Real avatar-based learning merupakan bagian dari simulasi untuk praktek dan ujian praktek mahasiswa yang didesign hampir sama dengan kondisi rumah sakit. Skruktur real avatarbased learning terdiri dari interactive real virtual learning, learning task dan learning feed back.

Interactive real virtual learning merupakan upaya mendesain laboratorium khusus untuk simulasi yang dibuat sesuai dengan kondisi di Rumah Sakit yang lengkap dengan peralatan dan stafnya. Sedangkan learning task merupakan skenario kasus yang akan dianalisis mahasiswa sebagaimana layaknya rekam medik pasien. Mahasiswa dapat melakukan pengkajian melalui wawancara untuk kemudian menentukan diagnosa keperawatan, menenantukan prioritas masalah, membuat perencanaan, melakukan implementasi, dan melakukukan evaluasi keperawatan. Sedangkan learning feed back merupakan upaya yang dilakukan oleh mahasiswa untuk mengatasi kesulitan dengan cara studi literatur yang telah disediakan sebelumnya, atau bertanya kepada staf laiinya. Waktu yang diberikan pada fase ini adalah 1 jam. Jumlah responden ditentukan dengan menggunakan G-Power Software Version 3.1.6 dengan asusmsi uji t, $a=0.05$, effect size $=0.25$ (Cohen, 1992), power level $=0.80,2$ kali pengukuran. Responden yang terlibat dalam penelitian ini sebanyak 40 orang mahasiswa.

Self-Directed Learning diukur dengan menggunakan Self-Directed Learning Instrument (SDLI) yang dikembangkan oleh Cheng (2010). Instrumen ini terdiri dari 20 pertanyaan yang terdapat dalam 4 domain yaitu: motivasi belajar, perencanaan dan implementasi, self-monitoring dan komunikasi interpersonal. Terdiri dari skala likert 1 sampai 5, 1 menjukan tidak setuju sedangkan 5 menunjukan sangat setuju. Intrument in memiliki nilai cronbach's alpha yang bagus, 0.916 untuk total skor, 0.765-0.861 untuk setiap domain nya. Instrumen ini diterjemahkan kedalam Bahasa Indonesia dengan metode forward dan backward kemudian dilakukankan konten validitas melalui ahli dibidang keperawatan. Berdasarkan hasil content validity ke-5 ahli dibidang pendidikan keperawatan dengan pendidikan minimal S1 keperawatan, nilai content validity index (CVI) nya adalah 0.83 .

Perbedaan rerata skor SDL sebelum dan sesudah perlakuan dianalisis dengan uji $t$ berpasangan dengan tingkat signifikasa 5\%. Program statistik yang digunakan adalah SPSS versi 22 untuk Window.

\section{HASIL PENELITIAN}

Pengambilan data penelitian dilaksanakan sebelum responden mengikuti program real avatar-based learning (pretest) dan satu bulan setelah program tersebut diberikan (postest). Responden penelitian yang berjumlah 40 orang tersebut merupakan mahasiswa keperawatan S1 tingkat 4 STIKEP PPNI Jawa Barat. 


\section{Karakteristik Responden}

Sebagian besar mahasiswa adalah perempuan $(87.5 \%)$, usia ratarata $19.56(\mathrm{SD}=1.37)$, dan nilai indek prestasi kumulatif (IPK) berada dalam rentang 2.95 - 3.56. Berdasarkan hasil analisa pada pre-test mengenail selfdirected learning mahasiswa, didapatkan data bahwa sebagian besar $(90 \%)$ mahasiswa membutuhkan feedback yang cepat dari dosen ketika mereka memiliki pertanyaan atau mengahadapi suatu masalah yang berkaitan dengan mata kuliah dan praktikum. Selain itu sebanyak $\quad 87.5 \% \quad$ mahasiswa membutuhkan banyak simulasi untuk memahami tindakan keperawatan di laboratorium dengan konsep yang mirip kondisi rumah sakit. Sebanyak $87.5 \%$ mahasiswa berharap bisa mendapatkan fasilitas yang menerapkan teknologi dalam proses pembelajarannya.

\section{Efektvitas real avatar-based learning}

Efektivtas dari program real avatarbased learning dapat dilihat pada Tabel 1.

\section{Tabel 1. Efektifitas real-avatar-based learning terhadap self-directed learning pada mahasiswa keperawatan tingkat IV $(n=40)$}

\begin{tabular}{|c|c|c|c|c|}
\hline & $\begin{array}{l}\text { Pre-test } \\
\text { Mean (SD) }\end{array}$ & $\begin{array}{c}\text { Post-test } \\
\text { Mean (SD) }\end{array}$ & $\begin{array}{l}p- \\
\text { value }\end{array}$ & $\begin{array}{l}\text { Nilai } \\
\text { Beda } \\
\end{array}$ \\
\hline $\begin{array}{l}\text { Total skor } \\
\text { self-directed } \\
\text { learning } \\
\text { Domain skor }\end{array}$ & $\begin{array}{c}72.3 \\
(\mathrm{SD}=8.97)\end{array}$ & $\begin{array}{c}80.6 \\
(S D=13.9)\end{array}$ & 0.001 & 4.56 \\
\hline $\begin{array}{l}\text { Motivasi } \\
\text { belajar }\end{array}$ & $\begin{array}{c}33.7 \\
(\mathrm{SD}=5.62)\end{array}$ & $\begin{array}{c}35.2 \\
(\mathrm{SD}=1.34)\end{array}$ & 0.04 & 2.19 \\
\hline $\begin{array}{l}\text { perencanaan } \\
\text { dan } \\
\text { implementasi }\end{array}$ & $\begin{array}{c}22.6 \\
(\mathrm{SD}=4.51)\end{array}$ & $\begin{array}{c}30.8 \\
(\mathrm{SD}=9.03)\end{array}$ & 0.001 & 5.98 \\
\hline $\begin{array}{l}\text { Self- } \\
\text { monitoring }\end{array}$ & $\begin{array}{c}19.1 \\
(S D=3.71)\end{array}$ & $\begin{array}{c}24.3 \\
(\mathrm{SD}=5.17)\end{array}$ & 0.001 & 3.56 \\
\hline $\begin{array}{l}\text { Komunikasi } \\
\text { interpersonal }\end{array}$ & $\begin{array}{c}21.9 \\
(\mathrm{SD}=6.98)\end{array}$ & $\begin{array}{c}26.7 \\
(S D=8.31)\end{array}$ & 0.025 & 3.01 \\
\hline
\end{tabular}

Sebelum dilakukan interventi, nilai rata-rata untuk total skor selfdirected learning adalah 72.3 (SD=8.97). Domain yang tertinggi adalah komunikasi interpersonal dengan skor rata-rata sebesar 19.35 (SD=4.57), diikuti oleh motivasi belajar $(18.67, \quad S D=3.45)$. Sedangkan skor terendah ada di domain perencanaan dan implementasi serta self-monitoring.

Berdasarkan hasil paired t test di dapat hasil bahwa program real-avatarbased learning dapat meningkatkan selfdirected learning didapatkan data bahwa setelah diterapkan real-avatar basedlearning pada saat praktikum untuk mata kuliah KMB III terjadi peningkatan selfdirected learning sebesar 3,56. Hal ini ditunjukan oleh nilai $p=0,001$ dan nilai beda $=3,56$.

\section{PEMBAHASAN}

Hasil penelitian ini menunjukan bahwan real avatar-based learning efektif dalam meningkatkan self-directed learning mahasiswa. Metode ini merupakan bagian dari simulasi dengan seting sesuai dengan kondisi rumah sakit dan kasus yang dirancang merupakan kasus nyata yang ada di rumah sakit. Ini merupakan metode pertama yang diterapkan di Indonesia dengan mengadopsi sistem avatar-based learning yang dilakukan dengan mengunakan visualisai teknologi informasi dan komputer. Self-directed learning merupakan salah satu indikator dari kompetensi pendidikan keperawatan yaitu pembelajaran sepanjang hayat (lifelong learning). Sehingga peningkatan kompetensi ini sangat penting untuk diperhatikan dalam pendidikan keperawatan, karena pendidikan itu berkelanjutan dan tidak akan pernah ada hentinya. Peningkatan stimulus selfdirected learning perlu dikembangkan 
dalam pendidikan kepearawatan sangat diperlukan.

Penelitian serupa dengan pemanfaatan teknologi informasi dan komputer yang dilakukan di Australia dengan metode randomized controlled trial menunjukan bahwa avatar-based learning efektif dalam meningkatan keterampilan mahasiswa keperawatan dari mulai pengkajian sampai dengan evaluasi, disamping itu mahasiswa juga melaporkan tingkat kepuasan yang tinggi dengan penerapan metode ini (O'Flaherty, 2014). Studi lain yang dilakukan oleh Claman (2014) di Amerika Serikat menujukan bahwa dengan pengunaan simulasi yang nyata meningkatkan komunikasi dan keterlibatan aktif mahasiswa dalam proses pembelajaran. Selain itu Choi (2014) menegasakan bahwa penggunaan pembelajaran dengan metode virtual itu bisa diaplikasikan juga untuk tindakan khusus seperti pemasangan nasogatrik tub (NGT), dimana proses ini jika hanya dilaksanakan praktik saja tanpa ada skenario yang komprehensif itu tidak mampu meningkatkan sense of feeling mahasiswa.

Berdasarkan kajian aspek selfdirected learning bahwa sebagian besar dari mahasiswa membutuhkan respon yang cepat ketika mereka mengalami kesulitan baik. Metode real avatar-based learning ini merupakan metode yang efektif karena ketika mahasiswa memiliki kesulitas, mereka sudah disediakan berbagai sumber (dalam hal ini jurnal dan buku-buku) yang lengkap yang berkaitan dengan materi. Sehingga mereka bisa dengan cepat memecahkan masalah atau kesulitan yang dihadapi. Respon yang cepat dalam proses pembelajaran merupakan suatu hal yang penting yang terkadang kurang diperhatikan. Pembelajaran adalah proses timbal balik sehingga dalam memenuhi tantangan seperti ini diharapkan dosen mulai memiliki kepekaan untuk segera merespon yang menjadi keluhan siswa. Penggunaan media sosial seperti free group chatting bisa menjadi alternatif untuk meningkatan respon terhadap kesulitas mahasiswa.

\section{SIMPULAN DAN SARAN}

Penelitian ini menunjukan bahwa real avatar-based learning efektif dalam meningkatkan self-directed learning mahasiswa terutama pada aspek peningkatan perencanaan dan implementasi serta self-monitoring. Selfdirected learning merupakan salah satu indikator dari kompetensi pendidikan keperawatan yaitu pembelajaran sepanjang hayat (life-long learning). Merancang metode pembelajaran yang mampu meningakatan self-directed learning mahasiswa sangat penting. Respon yang cepat merupakan salah satu aspek dari self-directed learning yang menjadi fokus kebutuhan mahasiswa. Penggunaan media sosial seperti free group chatting bisa menjadi alternatif untuk meningkatan respon terhadap kesulitan mahasiswa.

\section{UCAPAN TERIMAKASIH}

Terima kasih kepada Ristekdikti yang sudah membiayai penelitian ini pada skema dosen pemula tahun 2017.

\section{DAFTAR PUSTAKA}

Anderson, J.Page,A.Wendrof,D. (2013). Avatar-Assisted Case Studies. Nurse Educator. Vol. 38, No.3,pp.106-109.doi: 10.1097/NNE.0b013e31828dc26 0. 
American Nurse Association. (1980).

Definition of nursing.

Available from

http://www.icn.ch/who-we-

are/icn-definition-of-nursing/.

Assosiasi Pendidikan Ners Indonesia.

(2015). Pendidikan dan

kurikulum keperawatan Available

from

http://www.kmshpeq.net/doc/ko

mp1/1_10/10_008/2_2_018_201

10500_ kurikulum_

kbk_aipni_2010.pdf.

Jones, T. Bowen,L.Morris,A. (2015).

Enhancing nursing students' understanding of threshold concepts through the use of digital stories and a virtual community called 'Wiimali'. Nurse Education in practices; 15; 91-96.doi.

http://dx.doi.org/10.1016/j.nepr.2 $\underline{014.11 .014 .}$.

Calman, F.(2014). The impact of multiuser virtual environments on student engagement. Nurse Education in Practice; 15:13-16.doi.

http://dx.doi.org/10.1016/j.nepr.2 $\underline{014.11 .006 .}$.

Choi., et al. (2015). A virtual reality based simulator for learning nasogastric tube placement.
Computers in Biology and Medicine;57:103-115.doi: http://dx.doi.org/10.1016/j.compb iomed.2014.12.006.

Flood,J.Commendador,K.(2016). Avatar Case Studies A Learning Activity to Bridge the Gap Between Classroom and Clinical Practice in Nursing Education. Nurse Educator. Vol. 41, No. 1, pp. 3-4. Doi.

10.1097/NNE.000000000000019 5.

Liaw, eta al.(2014). Comparison of Virtual Patient Simulation With Mannequin Based Simulation for Improving Clinical Performances in Assessing and Managing Clinical Deterioration: Randomized Controlled Trial. Med Internet Res; 16(9): e214. doi: 10.2196/jmir.3322.

Menzel, et al.(2014). Effectiveness of a Poverty Simulation in Second Life $®$ : Changing Nursing Student Attitudes toward Poor People. International Journal of Nursing Education Scholarship; 11(1): 17. doi 10.1515/ijnes-2013-0076.

O'Flaherty,J.Laws,T. (2014). Nursing student's evaluation of a virtual classroom. 